\title{
Los mamíferos del Mioceno y Plioceno de Espinar (Cusco): antecedentes y proyecto
}

Julia Tejada, Jorge Gamarra y Rodolfo Salas-Gismondi

\section{(2) OpenEdition}

1 Journals

Edición electrónica

URL: http://journals.openedition.org/bifea/2881

DOI: 10.4000/bifea.2881

ISSN: 2076-5827

Editor

Institut Français d'Études Andines

Edición impresa

Fecha de publicación: 1 abril 2009

Paginación: 133-135

ISSN: 0303-7495

\section{Referencia electrónica}

Julia Tejada, Jorge Gamarra y Rodolfo Salas-Gismondi, « Los mamíferos del Mioceno y Plioceno de

Espinar (Cusco): antecedentes y proyecto ", Bulletin de l'Institut français d'études andines [En línea], 38

(1) | 2009, Publicado el 01 octubre 2009, consultado el 17 noviembre 2020. URL : http://

journals.openedition.org/bifea/2881; DOI : https://doi.org/10.4000/bifea.2881

\section{cc)}

Les contenus du Bulletin de l'Institut français d'études andines sont mis à disposition selon les termes de la licence Creative Commons Attribution - Pas d'Utilisation Commerciale - Pas de Modification 4.0 International. 


\title{
Los mamíferos del Mioceno y Plioceno de Espinar (Cusco): antecedentes y proyecto
}

\author{
Julia Tejada ${ }^{*, * *}$, Jorge Gamarra ${ }^{* * *}$, Rodolfo Salas-Gismondi ${ }^{* *}$
}

En noviembre de 2002, durante la obra de excavación de un reservorio de agua para irrigación, trabajadores de la Villa Accocunca (Alto Pichigua) se toparon con los restos fosilizados de un gran «armadillo», a casi tres metros de profundidad. Durante el proceso de colecta, realizado por uno de los autores (JG), colaboradores del INC-CUS y pobladores locales, solo fue posible apreciar el caparazón, los anillos y el tubo caudal. Sin embargo, la limpieza y conservación de los huesos en el laboratorio reveló la existencia del esqueleto completo en el interior del caparazón. Las extremidades estaban dobladas y la cabeza recogida e inclinada ventralmente de tal manera que el escudo cefálico, ubicado en la región frontal del cráneo, cerraba con precisión la abertura delantera del caparazón. Los pobladores de Alto Pichigua celebraron una fiesta en honor al difunto exhumado. En los años siguientes, nuevos hallazgos en la región fueron claros indicadores de la existencia de un importante yacimiento de vertebrados fósiles en la provincia de Espinar, Cusco.

La provincia de Espinar se sitúa en el sur del departamento de Cusco, a una altitud promedio de $4000 \mathrm{~m}$. Su clima, propio de la puna, es frío y seco. El área fosilífera se ubica en la llamada altiplanicie o cubeta Yauri, inmediata al extremo noroeste del gran Altiplano Andino, entre los $14^{\circ} 40^{\prime}$ y $15^{\circ} 00^{\prime} \mathrm{S}$ de latitud y los $71^{\circ} 10^{\prime}$ y $71^{\circ} 30^{\prime} \mathrm{O}$ de longitud. El paisaje está dominado por extensas mesetas excavadas por ríos menores y arroyos pertenecientes a la cuenca alta del río Apurimac y a la subcuenca del río Salado (fig. 1). Los restos óseos, descubiertos en estas mesetas, proceden de las Formaciones (Fm) Casablanca y Yauri (De La Cruz, 1995; Fm El Descanso, Miembro Principal y Fm El Descanso, Miembro Cuspidal de Cerpa et al., 2004, respectivamente). Dataciones $\mathrm{Ar} / \mathrm{Ar}$ obtenidas de la llamada toba Yauri (Fm Pampa Garzas de De La Cruz, 1995), ubicada estratégicamente entre ambas formaciones, indican una edad aproximada de 12 Ma (Cerpa et al., 2004). La tasa de sedimentación estimada en la Fm Casablanca ( 100-110 m/Ma) y extrapolada para la Fm

\footnotetext{
* Instituto Francés de Estudios Andinos (IFEA), Av. Arequipa 4500, Lima 18, Perú. E-mail: juliatejada@gmail.com

** Museo de Historia Natural-UNMSM, Departamento de Paleontología de Vertebrados, Av. Arenales 1256, Lima 14, Perú. E-mail: rodsalasgis@yahoo.com

*** Instituto Regional de Cultura, Cusco (INC-CUS). E-mail: jorgeluisgamarragamio@yahoo.es
} 


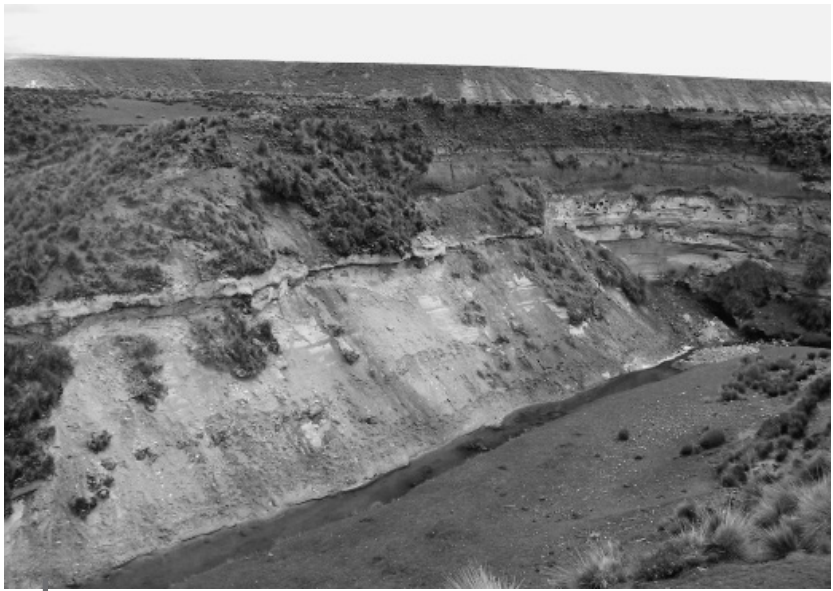

Figura 1 - Vista general de los afloramientos de la Formación Yauri en la Quebrada Pacchamayo, localidad de Huanu Huanu, Espinar
Yauri, sugiere que los depósitos más jóvenes de ésta última no superarían el Mioceno medio ( $10 \mathrm{Ma}$; Cerpa et al., 2004). Nuestra observación preliminar de los vertebrados descubiertos muestra:

(1) únicamente mamíferos nativos sudamericanos;

(2) una forma procedente de la Fm Yauri característica del Plioceno.

Consideramos que la edad de las rocas con vertebrados fueron depositadas en el lapso Mioceno medio-Plioceno ?medio ( 14-3 Ma). En general, el ambiente de depositación cambia en el tiempo de un sistema fluvial a uno de tipo lacustre, con secuencias de alta energía en el primero y aguas tranquilas con abundantes diatomeas en el segundo (De La Cruz, 1995).

Hasta la fecha se ha identificado una localidad fosilífera con vertebrados perteneciente a la sección superior de la Fm Casablanca (i.e. Alto Pichigua) y dos a la Fm Yauri (i.e. Huanu Huanu y ciudad de Yauri). Los xenartros son el grupo más diverso, representados esencialmente por gliptodontes de las subfamilias Hoplophorinae y Glyptodontinae; existe también registro de un Phyllophaga indeterminado. Entre los notoungulados, varios especímenes indican la presencia de un toxodóntido atribuido al género Posnanskytherium, solo conocido previamente en el Plioceno del altiplano boliviano (e.g. Anaya \& MacFadden, 1995; Saint-André, 1999). Los fósiles fueron colectados, preparados y conservados por personal del Laboratorio Físico-Químico del Instituto Nacional de Cultura del Cusco.

El proyecto «Primera fauna nativa del MioPlioceno del Perú (Espinar, Cusco): un vistazo a la historia evolutiva del ecosistema altiplánico de Perú y Bolivia» estudiará los fósiles de vertebrados de la provincia de Espinar con el propósito de conocer las últimas comunidades endémicas de mamíferos previas al arribo de la fauna inmigrante de origen holártico, como consecuencia de la instauración del istmo de Panamá. En general, es una época conocida parcialmente en Sudamérica y documentada por primera vez en el territorio peruano. El extraordinario estado de conservación de los fósiles —como es el caso del espécimen de Alto Pichigua (fig. 2)- permite acceder a detalles de la anatomía sistemática y funcional de algunos animales antes solo identificados a través de restos fragmentarios. Por otro lado, en escasos lugares del mundo existe la posibilidad de registrar la fauna de dos o más momentos geológicos próximos en un área geográfica

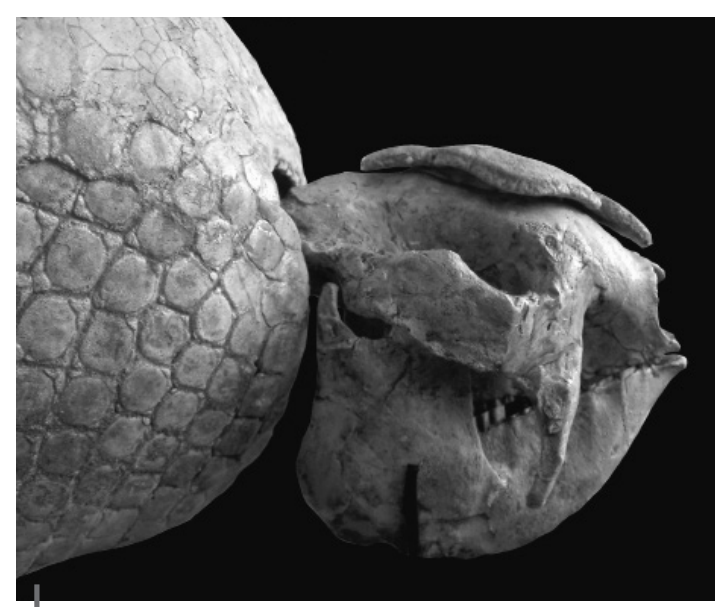

Figura 2 - Gliptodonte Hoplophorinae (INC CUS 6) descubierto en los afloramientos de la Formación Casablanca, localidad de Alto Pichigua y actualmente en exhibición en el Municipio de ese distrito Longitud del cráneo: $\sim 20 \mathrm{~cm}$ 
relativamente pequeña. Con el apoyo de mayores precisiones cronológicas de las rocas de las formaciones Casablanca y Yauri, se podrá observar la evolución y relaciones de parentesco de los grupos descritos, así como la historia ecológica y climática del ecosistema altiplánico durante el Mioceno y Plioceno. La evidencia basada en algunos fósiles de Espinar y del Altiplano boliviano sugiere que esta región estuvo sujeta en el pasado a cierto aislamiento ecológico.

Uno de los aportes fundamentales de este proyecto es apoyar en la protección del importante patrimonio paleontológico de la región, para lo cual se han previsto dos acciones importantes: la primera es la creación legal y física de un Laboratorio de Paleontología de Vertebrados en el INC-Cusco que desarrolle una activa labor en el rescate y la conservación de los fósiles locales; la segunda propone crear conciencia entre las autoridades y pobladores de Espinar - a través de charlas y exhibiciones - sobre la necesidad de cuidar y valorar los restos paleontológicos. En tal sentido, el IFEA y el INC-CUS se han comprometido en colaborar enérgicamente con el propósito de lograr los objetivos científicos y sociales del presente proyecto.

\section{Agradecimientos}

Este proyecto es financiado por el IFEA gracias a una beca de investigación científica obtenida por J. Tejada.

Agradecemos a los descubridores Rufino Laucata Tarifa, Fidel Tarifa Laucata, Valentín Charca Sayo, Adolfo Champú, Roshil Pila Condori, Mario Campos Quispe, Julio Remigio Chara, Aidee Pocco y a todos los pobladores locales que colaboraron en el rescate de los fósiles de Espinar. Agradecemos también a Eliana Rojas Velásquez, Claudio Cumpa Palacios y Aquiles Choque del Laboratorio FísicoQuímico del INC-CUS por la excavación, colecta, preparación, conservación y armado de los restos paleontológicos. Al Municipio de Espinar y Alto Pichigua por el continuo apoyo prestado. Se agradece a Enrique Bostelmann, Gustavo Jara y Diego Báez por su apoyo y comentarios.

\section{Referencias citadas}

ANAYA, F., \& MACFADDEN, B., 1995 - Pliocene mammals from Inchasi, Bolivia: the endemic fauna just before the Great American Interchange. Bulletin of the Florida Museum of Natural History, 39 (3): 87-140.

CERPA, L., MEZA, P., CARLOTTO, V., FORNARI, M. \& SEMPERE, T., 2004 - Paleogeografía y evolución de la Cuenca Miocena de Descanso-Yauri (Cusco). In: Nuevas contribuciones del IRD y sus contrapartes al conocimiento geológico del sur del Perú (Javier Jacay \& Thierry Sempere, eds.): 175-182; Lima: Publicación Especial de la Sociedad Geológica del Perú $\mathrm{n}^{\circ} 5$.

DE LA CRUZ, N., 1995 - Geología de los cuadrángulos de Velille, Yauri, Ayaviri y Azángaro. Boletín del Instituto Geológico, Minero y Metalúrgico, Serie A: Carta Geológica Nacional, 58: 1-144.

SAINT-ANDRÉ, P.-A., 1999 - Les Toxodontidés du Neogène de I'Altiplano bolivien. Paleontographica Abt. A, 251 (5-6): 79-148. 